\title{
Prostacyclin (epoprostenol) and heart-lung transplantation as treatments for severe pulmonary hypertension
}

\author{
T W Higenbottam, D Spiegelhalter, J P Scott, V Fuster, A T Dinh-Xuan, N Caine, \\ J Wallwork
}

\begin{abstract}
Objective-To determine whether epoprostenol (prostacyclin, PGI ${ }_{2}$ ) or heartlung transplantation (HLT), or both improves survival of patients with severe pulmonary hypertension.

Design-This was a prospective study where the effects of epoprostenol were compared with conventional treatment. Also, the benefits of epoprostenol and HLT were assessed by comparing survival in this group with that of 120 patients at the Mayo Clinic before HLT and epoprostenol treatment became available.

Patients and interventions-Forty four patients were studied; 25 received continuous epoprostenol over a four year period (mean (SD) cardiac index 1.8 $(0.4) 1 \mathrm{~min}^{-1} \mathrm{~m}^{-2}$ and mean (SD) pulmonary artery pressure (PAP) 70 (16) $\mathrm{mm} \mathrm{Hg}$ ) and 19 did not (cardiac index 2.1 $(0.6) 1 \mathrm{~min}^{-1} \mathrm{~m}^{-2}$ and PAP 64 (13) $\mathrm{mm} \mathrm{Hg}$ ). Ten patients underwent HLT: seven had received epoprostenol, and three had not.

Results-The therapeutic intervention with epoprostenol, or HLT, or both improved survival compared with the Mayo clinic patients $(p=0 \cdot 05)$. Most of the benefit was conferred by epoprostenol, which prolonged survival twofold from a median time of eight to 17 months and doubled the chances of successful HLT. The improved survival with epoprostenol was not related to its immediate capacity to cause pulmonary vasodilation. Those patients who had limited acute pulmonary vasodilation when treated with epoprostenol showed the greatest improvement in survival. Conclusions-These preliminary results indicate that those pulmonary hypertensive patients with the poorest chance of survival can be helped by epoprostenol and by HLT.
\end{abstract}

(Br Heart f 1993;70:366-370)

Unexplained and severe pulmonary hypertension is both uncommon and incurable. ${ }^{12}$ Recent treatments considered able to improve survival have included anticoagulants, ${ }^{3}$ vasodilators, ${ }^{4}$ and heart-lung ${ }^{5}$ or lung ${ }^{6}$ transplantation. Controlled and long-term studies of these treatments are rare and their efficacy has been questioned. ${ }^{7-9}$
Higenbottam et al reported a single patient in whom long-term intravenous infusion of epoprostenol lessened disability and apparently bought time for HLT. ${ }^{10}$ Further controlled studies of epoprostenol by Rubin et al reported not only sustained but a progressive improvement of pulmonary haemodynamics with long-term treatment. ${ }^{11}$

This study reports the comparison of survival among patients with severe pulmonary hypertension who received long-term epoprostenol and those who did not. Also, to assess whether epoprostenol or HLT or both improve survival; the survival of our patients was compared with that of patients from the Mayo clinic $^{3}$ who were studied before either HLT or epoprostenol were available.

\section{Patients and methods}

Over a six year period, 44 patients with severe pulmonary hypertension were entered into the study. None had congenital heart disease or evidence of thoracic or pulmonary disease on clinical or radiological examination or physiological tests. For comparison, the 120 patients from the Mayo clinic retrospective study for pulmonary hypertension were included. ${ }^{3}$

Standard electrocardiography and $M$ mode echocardiography with Doppler were undertaken, together with ventilation and perfusion lung scintigraphy. No patient was included with intracardiac shunts or atrial or ventricular septal defects. No patient was included with evidence of proximal pulmonary artery occlusion. ${ }^{12}$

Diagnostic right heart catheterisation was performed with a triple lumen flow directed catheter in all patients on entry to the study. ${ }^{13}$ A brachial artery cannula was also inserted.

In nine of the 44 patients it was not possible to record pulmonary artery wedge pressure. The total pulmonary vascular resistance (mean pulmonary artery pressure/cardiac index) was therefore calculated. A further measurement similar to that in the Mayo clinic study was included. The mixed venous oxygen saturation, together with arterial oxygen saturation were recorded from blood samples. The degree of disability was assessed by the New York Heart Association (NYHA) classification. ${ }^{14}$

The capacity to acutely vasodilate the pulmonary vasculature with epoprostenol was assessed in our patients during the catheter study. ${ }^{15}$ The infusion rate of epoprostenol was increased step wise every 10 minutes until the 
mean systemic artery pressure had fallen by $20 \%$ or more. ${ }^{13}$ At each stage, pulmonary artery pressure, cardiac index, and mixed venous and arterial oxygen saturations were measured.

All our patients were offered long-term epoprostenol infusion; the treatment was available on a named patient basis, but was purchased by the local health authority where the patient lives. In view of the expense, only 25 of the patients could be treated long-term.

Each patient treated with epoprostenol continued diuretic treatment but anticoagulants were stopped as were other forms of vasodilator treatment. The adequacy of treatment was assessed by means of progressive exercise tests $^{16}$ and a 12 minute walk test ${ }^{17}$ performed every three months. Deterioration of exercise tolerance led to an increased dose of epoprostenol. Patients with no opportunity for epoprostenol continued anticoagulant treatment and all were taking either nifedipine, $(<20 \mathrm{mg})$ or diltiazem $(<120 \mathrm{mg})$ three times daily. They too were given the same intensity of medical review at three monthly intervals.

For those 19 patients not receiving epoprostenol, suitable donors were sought from the time of initial assessment. In the 25 patients on epoprostenol, HLT was deferred until exercise tolerance had declined to initial levels despite progressive increases in dose of epoprostenol. At that point a donor was sought as in the patients not treated with epoprostenol.

\section{STATISTICAL ANALYSIS}

Actuarial survival from the date of the right heart catheter study was determined by Kaplan-Meier estimates. ${ }^{18}$ Cox's proportional hazard model enabled estimation of the relative risks associated with clinical state and haemodynamic variables. ${ }^{18}$ The effects of epoprostenol or HLT on survival were assessed with the Cox model in which HLT becomes a time dependent prognostic factor from the time of transplantation. ${ }^{18}$ This allowed determination of survival time to death or until transplant surgery. Comparisons of means were by two sample $t$ test and proportions by $\chi^{2}$ test.

\section{Results}

Our 44 patients were more severely affected by their disease than the 120 patients studied at the Mayo clinic (table 1). From the Cox proportional hazard model, the two populations did not differ in the variables that contributed most to poor prognosis (table 2). The most important were mixed venous oxygen saturation and NYHA class of disability (table 2). As a result pooled data are shown. Adjusting for severity, our 44 patients had a relative risk of death compared with the Mayo patients of 0.56 ( $95 \%$ confidence interval 0.31 to $1.00 ; p=0.05)$. The survival curves when adjusted to equivalent severity show clearly a superior survival in our patients (fig 1).
Table 1 Comparisons of vital statistics, functional state, and haemodynamic measurements in patients of the Mayo clinic and our study at the time of initial investigation

\begin{tabular}{|c|c|c|c|}
\hline & \multicolumn{2}{|l|}{ Patients } & \multirow[b]{2}{*}{$p$ Values } \\
\hline & Mayo clinic & Study & \\
\hline $\begin{array}{l}\text { Age (mean (SD) yr) } \\
\text { Sex }\end{array}$ & $\begin{array}{l}34(15) \\
87 \text { F (73\%) }\end{array}$ & $\begin{array}{l}37(12) \\
25 \mathrm{~F}(57 \%)\end{array}$ & 0.33 \\
\hline $\begin{array}{l}\text { NYHA class: } \\
\text { II } \\
\text { III } \\
\text { IV }\end{array}$ & $\begin{array}{l}34(28 \%) \\
81(68 \%) \\
5(4 \%)\end{array}$ & $\begin{array}{r}5(11 \%) \\
21(48 \%) \\
18(41 \%)\end{array}$ & $<0.0001$ \\
\hline $\begin{array}{l}\text { PAP (mm Hg): } \\
\text { Mean (SD) } \\
\text { Range }\end{array}$ & $\begin{array}{l}63(14) \\
45-98\end{array}$ & $\begin{array}{l}68(15) \\
40-101\end{array}$ & 0.05 \\
\hline $\begin{array}{l}\text { Cardiac index } \\
\left(1 \mathrm{~min}^{-1} \mathrm{~m}^{-2}:\right.\end{array}$ & & & \\
\hline $\begin{array}{l}\text { Mean (SD) } \\
\text { Range }\end{array}$ & $\begin{array}{l}2.2(0.9) \\
0.8-6.2\end{array}$ & $\begin{array}{l}2 \cdot 0(0.5) \\
1 \cdot 1-3.7\end{array}$ & $<0.05$ \\
\hline $\begin{array}{l}\text { TPR }\left(\mathrm{Um}^{2}\right) \\
\text { Mean (SD) } \\
\text { Range }\end{array}$ & $\begin{array}{l}31(13) \\
11-84\end{array}$ & $\begin{array}{l}37(14) \\
14-72\end{array}$ & $<0.001$ \\
\hline $\begin{array}{l}\mathrm{SvO}_{2}(\%) \\
\text { Mean (SD) } \\
\text { Range }\end{array}$ & $\begin{array}{l}60(12) \\
20-80\end{array}$ & $\begin{array}{l}54(12) \\
22-79\end{array}$ & $<0.01$ \\
\hline
\end{tabular}

PAP, mean pulmonary artery pressure; TPR, total pulmonary resistance; $\mathrm{SvO}_{2}$, mixed venous oxygen saturation

Table 2 Relative risks associated with clinical and haemodynamic measurements of patients from both the Mayo clinic and our study (Cox proportional hazard model stratified by centre)

\begin{tabular}{llc}
\hline Risk factors & Relative risks & p Values \\
\hline Age (/decade older) & 0.96 & 0.62 \\
NYHA (/grade increase) & 1.46 & 0.08 \\
PAP (/10 mm Hg increase) & 1.04 & 0.78 \\
Cardiac index (/unit decrease) & 1.00 & 0.98 \\
Svo $_{2}$ (/10\% decrease) & 1.67 & $<0.0001$ \\
\hline
\end{tabular}

Abbreviations as for table 1.

Most of the benefit in survival was attributable to epoprostenol. Although the 25 patients who received epoprostenol were similar to the 19 patients who did not, in terms of the variables determining prognosis (table 3 ), they had better one year survival (fig 2). By two years, survival was indistinguishable
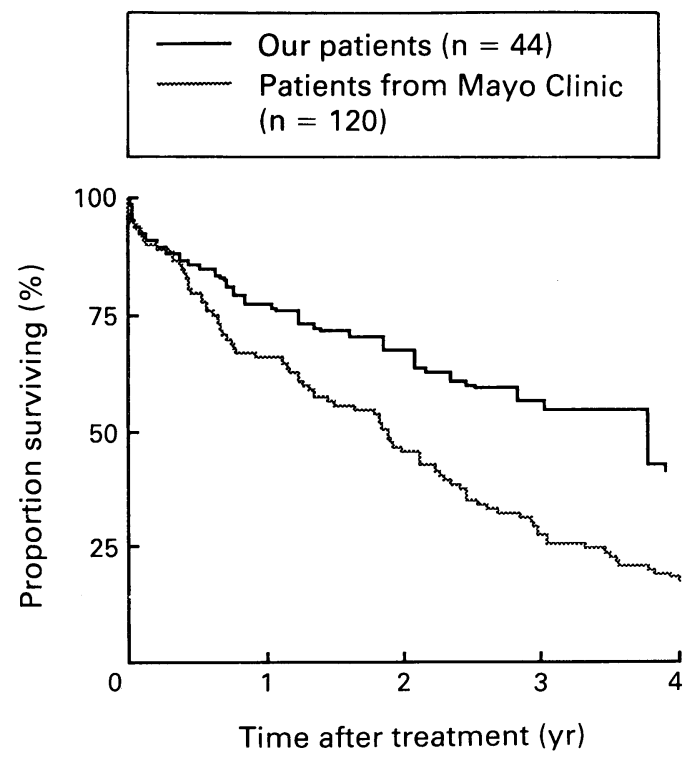

Figure 1 Benefit of epoprostenol or heart-lung transplantation on survival of an average patient from the study $(n=44)$ compared with that of an average patient from the Mayo clinic study $(n=120)$ before either treatment was available. Fixed NYHA class, age, pulmonary artery pressure, cardiac index, and mixed venous oxygen saturation. Adjusted by Cox proportional hazard model, stratified by centre. 
Table 3 Comparison of vital statistics, functional states and haemodynamic measurements of our patients who were either treated or not treated with long term intravenous epoprostenol (PGI $)$

\begin{tabular}{|c|c|c|c|}
\hline & $\begin{array}{l}\text { With PGI } \\
(n=25)\end{array}$ & $\begin{array}{l}\text { Without PGI } \\
(n=19)\end{array}$ & p Values \\
\hline Age (mean (SD)) & $35(10)$ & $39(15)$ & 0.21 \\
\hline II & 0 & 26 & \\
\hline III & 52 & 42 & 0.03 \\
\hline IV & 48 & 32 & 00 \\
\hline PAP (mean (SD)): & & & \\
\hline $\begin{array}{l}\text { Baseline (mm Hg) } \\
\text { \% Fall (on acute trial with } \mathrm{PGI}_{2} \text { ) }\end{array}$ & $\begin{array}{r}70(16) \\
4(13)\end{array}$ & $\begin{array}{r}64(13) \\
4(15)\end{array}$ & $\begin{array}{l}0 \cdot 19 \\
0.98\end{array}$ \\
\hline Cardiac index (mean (SD)): & & & \\
\hline $\begin{array}{l}\text { Baseline }\left(\mathrm{min}^{-1} \cdot \mathrm{m}^{-2}\right) \\
\text { \% Rise (on acute trial with } \mathrm{PGI}_{2} \text { ) } \\
\text { TPR (mean (SD)): }\end{array}$ & $\begin{array}{l}1 \cdot 8(0 \cdot 4) \\
39(24)\end{array}$ & $\begin{array}{l}2 \cdot 1(0 \cdot 6) \\
32(22)\end{array}$ & $\begin{array}{l}0.06 \\
0.32\end{array}$ \\
\hline $\begin{array}{l}\text { Baseline (Um²) } \\
\% \text { Fall (on acute trial with } \mathrm{PGI}_{2} \text { ) }\end{array}$ & $\begin{array}{l}41(15) \\
29(16)\end{array}$ & $\begin{array}{l}32(11) \\
26(17)\end{array}$ & $\begin{array}{l}0.04 \\
0.54\end{array}$ \\
\hline SVR (mean (SD)): & & & \\
\hline $\begin{array}{l}\text { Baseline (Wood units) } \\
\% \text { Fall (on acute trial with } \text { PGI }_{2} \text { ) } \\
\text { Svo }_{2}(\%) \text { (mean (SD)) }\end{array}$ & $\begin{array}{l}26(8) \\
31(14) \\
54(11)\end{array}$ & $\begin{array}{l}21(4) \\
27(17) \\
54(13)\end{array}$ & $\begin{array}{l}0.02 \\
0.40 \\
0.83\end{array}$ \\
\hline
\end{tabular}

SVR, systemic vascular reistance; other abbreviations as for table 1.

between the two groups. Epoprostenol effectively doubled the time on the waiting list or to death from a median of eight to 17 months, and doubled the chances of HLT (table 4). The mean (SD) dose of epoprostenol $_{2}$ was initially $5.2(0.5) \mathrm{ng} / \mathrm{kg} /$ min rising to the maximum dose of $18 \cdot 7(4 \cdot 5)$ $\mathrm{ng} / \mathrm{kg} / \mathrm{min}$ at death or at transplant surgery.

The patients who benefited from long-term survival with epoprostenol were those who showed $<33 \%$ rise in cardiac index (fig 3 ) and no fall in pulmonary artery pressure (fig 4) when a dose response to epoprostenol was undertaken during the right heart catheter study. Therefore those patients with the least ability to vasodilate with epoprostenol during an acute study showed the greatest benefits in terms of survival when treated with long-term epoprostenol. There was no difference, however, between the poorly responsive patients and those who vasodilated with epoprostenol in their mean mixed venous oxygen saturation, (55\% and $54 \%)$.

To consider the relative merits of epoprostenol and HLT, a Cox's regression was used with HLT being entered as the

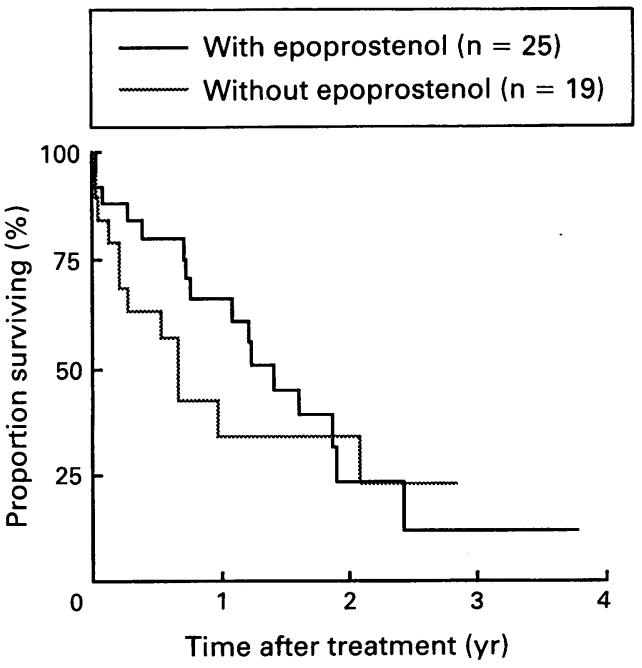

Figure 2 Improved survival until death or heart-lung transplantation (Kaplan-Meier curves) of patients treated with epoprostenol.
Table 4 Effects of long-term treatment with epoprostenol $\left(P \mathrm{I}_{2}\right)$ on the median time until death or transplantation (Kaplan-Meier estimate)

\begin{tabular}{lll}
\hline & $\begin{array}{l}\text { With PGI } \\
(n=25)\end{array}$ & $\begin{array}{l}\text { Without PGI } \\
(n=19)\end{array}$ \\
\hline $\begin{array}{l}\text { Median months } \\
\text { on waiting list } \\
\begin{array}{l}\text { Reason for coming } \\
\text { off list: }\end{array}\end{array}$ & 17 & 8 \\
$\begin{array}{l}\text { Transplant } \\
\text { Death }\end{array}$ & $7(44 \%)$ & $3(25 \%)$ \\
\hline
\end{tabular}

Table 5 Estimates of the benefits of epoprostenol (PGI ) and heart-lung transplantation (HLT) on survival adjusted for severity of risk factors with the Cox model

\begin{tabular}{lll}
\hline & Relative risks & $\begin{array}{l}95 \% \text { confidence } \\
\text { interval }\end{array}$ \\
\hline After PGI $_{2}$ & 0.34 & $(0 \cdot 10$ to $1 \cdot 14)$ \\
After $\mathrm{HLT}$ & 0.82 & $(0 \cdot 16$ to $4 \cdot 28)$ \\
\hline
\end{tabular}

Table 6 Results of heart-lung transplantation in the 10 transplanted patients

\begin{tabular}{lcc}
\hline & With PGI & Without PGI $_{2}$ \\
\hline No of patients & 7 & 3 \\
Current survivors & 3 & 1 \\
Causes of death: & 1 & - \\
$\quad$ Tracheal dehiscence & 0 & 1 \\
$\quad$ Cytomegalovirus pneumonia & 3 & - \\
$\quad$ Obliterative bronchiolitis & 3 & 1 \\
Median survival time (days) & 309 & 418
\end{tabular}

$\mathrm{PGI}_{2}$, epoprostenol.

time-dependent covariate and standardised for risk factors. Thus allowing for initial severity, epoprostenol reduces monthly mortality risk by $66 \%$ whereas HLT reduces the risk by $18 \%$ (table 5 ). A narrow confidence interval for epoprostenol ${ }_{2}$ adds some validity to its effect on survival whereas the wide limits for HLT as a result of the small numbers still leaves some uncertainty.

Of the 10 patients with HLT, four remain alive. There were no differences in causes of death between those that received epoprostenol and those that did not (table 6).

\section{Discussion}

We have shown that continuous long-term intravenous infusion of epoprostenol can improve survival in patients with severe pulmonary hypertension. Those patients with the least capacity to acutely vasodilate their pulmonary vasculature were the ones who gained most benefit (in terms of survival) from epoprostenol. Overall, this benefit accounted for most of the enhanced survival seen in our patients compared with the historical control group studied at the Mayo Clinic. Heart-lung transplantation conferred some survival benefit but the numbers were small. An approach to treatment of this progressive and usually fatal disease based upon severity can now tentatively be advanced.

Vasodilation treatment of patients with pulmonary hypertension is now advocated for those who during an acute trial of treatment show significant pulmonary vascular vasodilation. ${ }^{15} 19$ Fears have been expressed in the use 

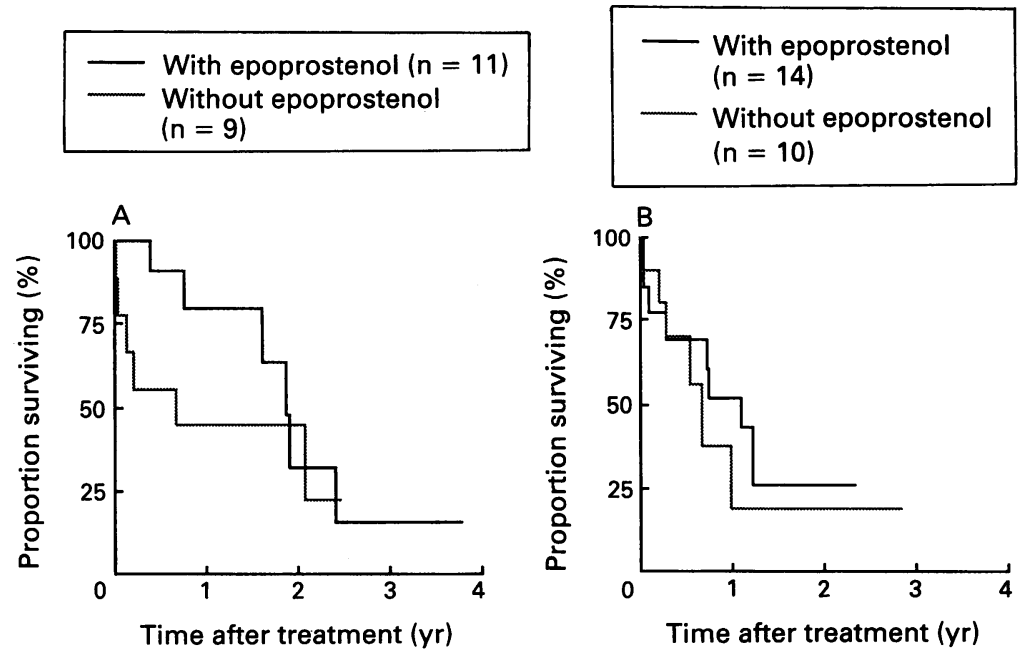

Figure 3 The main benefit in terms of survival (until death or transplantation) was in those patients who did not show a significant rise in cardiac index with acute infusion of epoprostenol $(A)$. Survival of patients who had vasodilatation with a rise of $33 \%$ in cardiac index if they received epoprostenol was no better than in those who were untreated $(B)$. tion during right heart catheter studies. In other words, its benefits in terms of survival are seen in those patients with advanced disease in whom the calcium channel blockers would not be advocated. This may not result from its powerful vasodilator properties but rather its role in inhibiting thrombus formation. ${ }^{23}$

Prostacyclin is one of the most powerful inhibitors of platelet aggregation and is used as an alternative to heparin for haemofiltration. ${ }^{23}$ Formation of small pulmonary arterial thrombus is a common feature in patients with primary pulmonary hypertension studied with open lung biopsy and at necropsy. ${ }^{24}$ Enhanced numbers of platelet aggregates and evidence of procoagulation have been described in patients with severe pulmonary hypertension associated with systemic sclerosis. ${ }^{25}$ Intravascular coagulation and thrombus formation are common in the lungs of patients with systemic lupus erythromatosis and pulmonary hypertension. ${ }^{26}$ The propensity to form thrombus in pulmonary arteries of patients with severe pulmonary hypertension has been ascribed to the low cardiac output seen in these patients. Recently an imbalance between the production of thromboxane $\mathrm{A}_{2}$ and prostacyclin has been suggested as a contributory factor. Increased production of the prothrombotic thromboxane $A_{2}$ and reduced prostacyclin production has been found in patients with advanced primary or unexplained pulmonary hypertension. ${ }^{27}$ Whether this represents the primary cause of the pulmonary hypertension, or is simply a consequence of advanced pulmonary vascular disease remains to be seen. Continuous long-term infusion of prostacyclin could potentially restore the balance of prostacyclin and thromboxane production and so perhaps impede the advance of thrombosis. This may account for the benefit provided by this treatment even in those patients where the capacity to undergo vasodilation has been lost.

Single lung transplantation ${ }^{6}$ and HLT $^{5}$ have been advocated for those patients whose haemodynamic measurements indicate a poor chance of survival. This is particularly the case with a cardiac index $<2 \mathrm{ml} \mathrm{min} \mathrm{m}^{-1} \mathrm{~m}^{-2}$, the pulmonary artery pressure $>60 \mathrm{~mm} \mathrm{Hg}$, mixed venous oxygen saturation $<60 \%$, and a right atrial pressure $>10 \mathrm{~mm} \mathrm{Hg}$. The longterm survival of patients with pulmonary hypertension after lung transplantation is perhaps less good than has been seen in those with interstitial and chronic airways disease. ${ }^{28}$ Further results of long-term studies are awaited with interest.

Despite these reservations, an approach to the treatment of pulmonary hypertension based upon severity of the disease can be advocated. At diagnostic right heart catheterisation, if acute pulmonary vasodilation can be shown, then high dose calcium channel blockers can be tried in those patients without high right atrial pressure. High daily doses of nifedipine and diltiazem can be attempted, used with both digoxin and
Figure 4 When a fall in mean pulmonary artery pressure (PAP) was an index of pulmonary vasodilatation with epoprostenol those patients with a fall in $P A P$ had the leas benefit in survival $(A)$. Conversely those with no vasodilatation had enhanced survival (B). 
diuretics. ${ }^{20}$ In those patients where vasodilation is not seen long-term infusion of epoprostenol can be advocated, even in the groups of patients with the worst prognosis epoprostenol buys time for lung transplantation.

We thank Mr Ben Milstein for his editorial advice. This work has been supported by grants from the British Heart Foundation. We also thank Mrs Alison Croker and Mrs Carolyn Williams for their patient work on the manuscript.

1 Walcott G, Burchell HB, Brown AL. Primary pulmonary hypertension. $A m$ F Med 1970;49:70-9.

2 Rich S, Dantzker DR, Ayres SM, et al. Primary pulmonary hypertension: a national prospective study. Ann Intern Med 1987;107:216-23.

3 Fuster V, Steele PM, Edwards WD, Gersh BJ, McGoon MD, Frye RL. Primary pulmonary hypertension: natural history and the importance of thrombosis. Circulation 1984;70:580-7.

4 Rich S, Brundage BH, Levy PS. The effect of vasodilator therapy on the clinical outcome of patients with primary therapy on the clinical outcome of patients with primary

5 Reitz BA, Wallwork J, Hunt SA, et al. Heart-lung transplantation: successful therapy for patients with pulmonary vascular disease. $N \mathrm{Engl} F \mathrm{Med} 1982 ; 306$ 557-64.

6 Levine SM, Gibbons WJ, Bryan CL, et al. Single lung transplanation for primary pulmonary hypertension. Chest 1990;98:1107-15.

7 Gatewood RP, Yu PN. Primary pulmonary hypertension. Progress in Cardiology 1929;8:305-49.

8 Packer $M$. Is it ethical to administer vasodilator drugs to patients with primary pulmonary hypertension? Chest 1989;95:1173-5.

9 Robin ED. The kingdom of the near-dead; the shortened irrational life history of primary pulmonary hypertension. Chest 1987;92:330-4.

10 Higenbottam TW, Wheeldon D, Wells FC, Wallwork J. Long-term treatment of primary pulmonary hypertension with continuous intravenous epoprostenol (prostacyclin). Lancet 1984;i:1046-7.

11 Rubin LJ, Mendosa J, Hood M, et al. Treatment of primary pulmonary hypertension with continuous intravenous prostacyclin (epoprostenol). Ann Int Med 1990; 112:485-91.

12 Rich S, Pietra GG, Kieras K, Hart K, Brundage BH. Primary pulmonary hypertension: radiographic and scintigraphic patterns of histologic subtypes. Ann Intern Med 1986;105:499-502.

13 Jones DK, Higenbottam TW, Wallwork J. Treatment of primary pulmonary hypertension with intravenous epoprostenol (prostacyclin). Br Heart $¥ 1987 ; 57: 270-8$.

14 The Criteria Committee of the New York Heart Association. Diseases of the heart and blood vessels; nomenAssociation. Diseases of the heart and blood vessels; nomen-
clature and criteria for diagnosis. 6th ed. Boston: Little Brown 1964.

15 Rozkovec A, Stradling JR, Shepherd G, MacDermot J, Oakley C, Dollery CT. Prediction of favourable responses to long-term vasodilation treatment of pulmonary hypertension by short term administration of epoprostenol (prostacyclin) or nifedipine. Br Heart $\mathscr{f}$ 1988;59:696-705.

16 D'Alonzo GE, Gianotte, Dantzker DR. Non-invasive assessment of haemodynamic improvement during chronic vasodilator therapy in obliterative pulmonary chronic vasodilator therapy in obliterative pulm

17 McGavin CR. Artvinli M, Naoe H, McHardy GJR Dyspnoea, disability and distance walked: comparison Dyspnoea, disability and distance walked: comparison of estimates of exercise perf

18 Cox DR, Oakes D. Analysis of survival data. London: Chapman and Hall, 1984:48, 91, 112

19 Reeves JT, Groves BM, Turkevich D. The case for treatment of selected patients with primary pulmonary hypertension. Am Rev Respir Dis 1986;134:342-6.

20 Palevsky H, Schloo BL, Pietra GG, et al. Primary pulmonary hypertension: vascular structure, morphometry and responsiveness to vasodilator agents. Circulation and responsiveness

21 Rich S, Kaufman E, Levy PS. The effect of high doses of calcium-channel blockers on survival in primary pulcalcium-channel blockers on survival in primary pul-
monary hypertension. $N$ Engl $¥ \mathrm{Med} 1992 ; 327: 76-81$.

22 Szczklik J, Szczeklik A, Nizankowski R. Haemodynamic changes induced by prostacyclin in man. Br Heart $\mathcal{F}$ 1980;44:254-8.

23 Moncada S. Biology and therapeutic potential of prostacyclin. Stroke 1983;14:157-68.

24 Peitra GG, Edwards WD, Kay JM, et al. Histopathology of primary pulmonary hypertension: a qualitative and quantitative study of blood vessels from 58 patients in que National Heart, Lung and Blood Institute primary the National Heart, Lung and Blood Institute primary pulmonary

25 Kahaleh MB, Osborn I, Leroy EC. Elevated levels of circulating platelet aggregates and beta-thromboglobulin in culating platelet aggregates and beta-thrombo

26 Asherson RA, Higenbottam TW, Dinh-Xuan AT Khamashta MA, Hughes GRV. I Rheumatol 1990;17: 1292-8.

27 Christian BW, McPherson CD, Newman JH, King GA Bernard GR, Groves BM, Lloyd JE. An imbalance between the excretion of thromboxane and prostacyclin metabolites in pulmonary hypertension. $N$ Engl f Med 1992;327:70-5.

28 McCarthy PM, Starnes VA, Theodore J, et al. Improved survival after heart-lung transplantation. $f$ Thorac Cardiovasc Surg 1990;99:54-60. 